\title{
Content Analysis of Published Articles in the South African Journal of Economic and Management Sciences
}

\author{
Yolanda Jordaan, Melanie Wiese, Karim Amade and Ermi de Clercq \\ Department of Marketing Management, University of Pretoria
}

Accepted: Junie 2013

\begin{abstract}
The publication of academic research is important for its contribution to the body of knowledge. A periodic analysis of journal content leads to the identification of research practices; while it also identifies the challenges that researchers face. The South African Journal of Economic and Management Sciences (SAJEMS) is considered to be one of the leading publications in the field of economic and managerial research in South Africa. The SAJEMS was selected as the unit of analysis; and a content analysis was conducted on 257 articles published during the seven-year period $2004-2010$. The main purpose of this study was to investigate the input and output factors relating to published articles, including questions on authors and article content, such as the various methodological approaches. The findings revealed that there has been a decrease in co-authored articles during the period $2005-2008$. Although the contribution by practitioners increased significantly in 2005 and 2008, the majority of the articles are still authored predominantly by academics. It is promising to see that international authors were involved in nearly 20 per cent of the articles contributed. When it came to the methodological approaches, the articles employed largely non-probability sampling designs. Furthermore, almost two-thirds of the articles published in SAJEMS were based on quantitative research designs. This content analysis reveals the current research practices published in the SAJEMS. It provides food for thought for academics.
\end{abstract}

Key words: content analysis, journal analysis, managerial research, South African Journal of Economic and Management Sciences, journal characteristics

JEL: M310, C830, M210

\section{1}

\section{Introduction}

Academic researchers regularly receive the most recent issues of various scholarly journals reporting on the latest academic research. However, rarely do research articles in such journals reflect on the research practices used by the other researchers who publish in them (Holbert, 1997). Holsapple, Johnson, Manakyan and Tanner (1993) argued that it is important to take stock periodically of the channels, such as journals, available for communicating scholarly discourse and research. Assessing the development, dissemination and use of knowledge in a field of study by examining its publication outlets at intervals provides consumers of the research, such as editors, academics and researchers, with a view of where the discipline has been and where it might be going (Bush \& Grant, 1994).
Taking stock of the content of journals has several benefits. First, it acts as a guide for potential authors regarding changes in content and methodology that might help direct future publications. Secondly, such reviews could reveal new opportunities for the journal, and could possibly identify areas relevant for special editions (Phelan, Ferreira \& Salvador, 2002). Additionally, it may help to reveal trends in the literature, identify gaps, assist journal editors in developing agendas for guiding future research efforts, and ultimately lead to publishing opportunities (Bush \& Grant, 1994).

The publication of academic research contributes to the body of knowledge, as it reveals insights that have been formulated and contextualised scientifically. When evaluating the contribution of academic research to the body of knowledge, one should examine the inputs and outputs of the published research (Bush \& Grant, 1994:59). 
Several previous studies have explored and analysed academic journals, predominantly in terms of their authorship, the institutions represented, the methodology followed and the topics covered (Albaum \& Peterson, 1984:161173; Yale \& Gilly, 1988:12-22; Kolbe \& Burnett, 1991:243-249; Hetzel, 2000; West, 2007:543-554). Other studies have analysed the outputs of academic research by focusing mainly on the content of an article, its length, the various research approaches and the theory-building trends (Inkpen \& Beamish, 1994; West, 2007; Beaty, Nkomo, \& Kriek, 2009).

When it comes to analysis of the content of South African journals, a few reviews have been conducted in the field of economic and management sciences (Clark, Dick, Epperecht, Du Plessis, Matlakala, Moremi, Raganya, Rich, Richards, Sewpershad \& Timm, 2002: 67; West, 2006:121; Baker, 2008:411; Brown \& Tanner, 2008:14). One study was conducted by Beaty et al. (2006), in which the writers reviewed the articles published from 1994 to 2004 in six South African management journals, including the South African Journal of Management Sciences, Management Dynamics and the Southern African Business Review. Another South African study conducted a joint investigation into the management literature published between 1996 and 2010 in the South African Journal of Economic and Management Sciences, Management Dynamics and the South African Journal of Business Management (Botha, Lilford \& Pitt, 2011).

In both South African studies, the investigations were broad, and only a few variables across several journals were analysed.

To date, no journal-specific investigation has been conducted into the state of the academic research published in the South African Journal of Economic and Management Sciences (SAJEMS). According to Botha et al. (2011:90), the SAJEMS is considered to be a prominent publication in interdisciplinary research in the field of economic and managerial research in South Africa and Africa. It is also one of the few accredited managerial journals in South Africa. Its status is confirmed by the fact that the SAJEMS is a refereed scientific journal, which is accredited by both Thomson Reuters in their Social Sciences Citation Index, and the South African Department of Education. The SAJEMS is also indexed and abstracted in EconLit (the electronic database of the Journal of Economic Literature).

The main purpose of this study is, therefore, to conduct a content analysis of the articles which appeared in the SAJEMS from 2004 to 2010 , with the aim of viewing the inputs and outputs of the published research in SAJEMS. If economic and management research is to progress, it is important for researchers to assess the methods they employ (Scandura \& Williams, 2000). This investigation aims to identify practices and possible challenges faced by the economic and management field and the journal per se.

\section{2}

\section{The literature review}

\subsection{The South African research environment}

A number of factors shape and affect the research environment in South Africa. The main characteristic of this environment is the increasing pressure under which academics find themselves to publish in peer-reviewed and/or accredited journals. The two institutions driving this process are the Department of Higher Education and Training (DHET) and the National Research Foundation (NRF).

In 2003, the DHET announced that Universities would qualify for subsidies for research output only if the publication in which an article appeared featured in the indices of the Institute of Scientific Research, or in the index of the International Bibliography of Social Sciences. Should the journal not be listed in any of the above, there is a special DHET-approved list of South African journals (updated annually) that are also eligible (Academy of Science of South Africa, 2010). South African academics are thus expected to publish in the listed journals in order to be recognised for their research output, but more importantly to receive DHET subsidisation for their respective institutions.

Another driver in terms of research is the NRF, which encourages researchers to obtain a rating via its Researcher Evaluation and Rating (RE \& R) initiative. This promotes and safe- 
guards research excellence, as well as ensuring that top researchers are easily identifiable. The ratings are conducted by researchers' peers, while the NRF manages the rating process. According to the rating system, researchers are evaluated and benchmarked based on the quality and impact of their previously-published academic research (Pouris, 2007:439). The focus of the rating system is international, the objective being to define the standing of researchers in the international arena (Vaughen, 2008). Researchers are allocated a rating (ranging from A to C), whereby an A-rating denotes researchers who are considered world leaders in their research field (MacGregor, 2008).

The process requires a researcher's outputs to be evaluated every five years by at least six expert referees, many of them from international institutions (Vaughen, 2008). Further, a researcher's rating affects his or her level of financial funding, as five-year grants, for example, are available only to rated researchers (Krige, 2007:57). Accordingly, there is a great deal of pressure on academics to obtain NRF ratings.

Both the DHET and NRF place emphasis on the publications in peer-reviewed journals, so it is important for researchers to understand how these publications work and what type of research they publish.

\subsection{Previous research into the state of journals}

An examination of the existing literature has shown that studies examining the content of academic journals typically focus on one or two (and sometimes both) of the following areas: factors that can be characterised as inputs, and those that can be categorised as outputs. Input factors concern mainly the authors of the articles published and include variables like the number of authors and the author affiliation. Output factors, on the other hand, concern mainly the articles presented for publication, and include variables like the length of articles and the methodologies employed in the study.

\subsubsection{Input factors: Authorship}

\subsubsection{Number of authors}

Both authors and institutions represent the inputs of journal articles. There has been a noticeable trend for articles to be published by two or more authors, showing a decrease in single authorship. Previous research shows that the single-authored article is in decline. Smart and Bayer (1986:297), Inkpen and Beamish (1994:707) and West (2007:547) have all found an increase in co-authored articles, especially those by two or three authors.

A possible explanation for this phenomenon is 'knowledge sophistication', which suggests an increase in interdisciplinary topics, and advances in statistical techniques and analyticcal software, which are conducive to the involvement of more expertise (Manton \& English, 2007:166). This knowledge sophistication consequently requires more expertise than a single author may possess, which explains the increased need for co-authorship.

\subsubsection{Affiliation of article author(s)}

Author affiliation is another area that has received extensive coverage in studies examining the content of scientific journals. Recent studies have pointed to the blurring of international borders owing to the advent of the digital age, which has resulted in an increasingly cosmopolitan body of authors in several academic publications. Chan, Karolyi and Rhee (2002), Otchere (2003) and West (2007) all found a significant contribution by foreign authors when they examined the contributor base of the Pacific Basin Finance Journal, Finance and Accounting, and the International Journal of Advertising.

Another common theme identified by previous studies was the noticeable prevalence of authors affiliated with a journal's home institution. Gallagher (2006:149), for example, found that the institution with the most articles published in the Australian Management Journal was the Australian Graduate School of Management, the home institution of the journal. This belonged to the University of New South Wales, which ranked second. The trend was supported by findings from a study by Otchere (2003:220) showing that there was a strong correlation between the editor's home institution and the institutions that published the specific journal.

Another issue associated with author affiliation relates to academics as opposed to practitioners as authors, with international 
research reporting a divide between the two groups (Tapp, 2004; Brennan, 2004). Research by Hetzel (2000:702) revealed that only 11 per cent of French academics who publish spend any time working in industry. A few years later, Otchere (2003:219) determined that only 4 per cent of articles published in Accounting and Finance had non-academic participation. West (2007:548) confirmed this notion when he revealed that the majority of authors in a specific journal were academics, with only 2 per cent of articles for the years 2002 to 2006 being written by practitioners.

According to Inkpen and Beamish (1994: 703) and Malhotra (1996:53), an investigation of authorship is important, as the author determines the topic, the methodology, the research objectives and the target population. This has served as the motivation to investigate the authorial practices in articles published in the SAJEMS.

\subsubsection{Outputs: Article contents}

\subsubsection{Research methodologies used by authors}

One of the most popular platforms for examining the contents of an academic article is the research method followed. Empirical research refers to observation and propositions based on observation and/or derived from "such experience methods as inductive logic, including mathematics and statistics" (Cooper \& Schindler, 2008:71). A general observation is that empirical methods are popular in the management sciences, with surveys being the most widely used. Bush and Grant (1994:62) reported that using surveys represented almost half of the total number of methods employed.

In a study examining the articles published in six publications, the Journal of Advertising, the Journal of Advertising Research, the Journal of Marketing, the Journal of Marketing Research, Current Issues and Research in Advertising, and the Journal of Consumer Research, it was found that 70 per cent of the published studies could be described as being empirical in nature (Yale \& Gilly, 1988:17). A total of 70 per cent of the articles published in the International Journal of Advertising for the period 1992 - 2006 also used empirical methods (West, 2007:549).
This is the same percentage as that found by Yale and Gilly (1988), which suggests that not much has changed in this regard.

A study examining research trends in the Academy Management Journal, Administrative Science Quarterly and the Journal of Management found that there has been a decrease in the number of literature review/ pure conceptual studies. The same study found that survey research accounted for just 3.6 per cent of all published studies (Scandura \& Williams, 2000:1256). In 2006, Svensson (2006: 1161) reported that 120 of the 150 articles published in the European Journal of Marketing during the period 2000 - 2004 used quantitative research methods. Following Svensson's study, Nilsson, Flores, Berkel, Schale, Linnemeyer and Summer (2007:606) confirmed that the majority of articles (79.8 per cent) used quantitative research methods.

In the same year, Hanson and Grimmer (2007:63-64) investigated 1195 academic journal articles for the period 1993 - 2002; and they also concluded that only 6.5 per cent of the articles included qualitative research methods, thereby confirming the extensive use of quantitative research methods.

\subsubsection{Sampling designs}

Albaum and Peterson (1984:167) identified non-probability sampling as the main choice of sample design in the Journal of International Business Studies. Poon and Rowley (2007) also found that non-probability sampling was used in the majority of instances, together with convenience and judgemental sampling.

The findings by West (2007) indicated that professionals were the group most commonly sampled in studies published in the International Journal of Advertising. These findings were in line with those by Scandura and Williams (2000), who showed that managers and professionals (23.3 per cent) were the most frequently-used sample units, followed by mixed studies (11.9 per cent) and students (10.7 per cent). Chia-Ping (2003) found that only 13 per cent of the articles in three management and information journals did not describe the sample frame, and that the majority of sample frames referred to geographic locations or commercial lists. 


\subsubsection{Statistical methods}

Gupta, Verma and Victorino (2006:436-437) reviewed 150 articles published in the Production and Management Journal from 1992 - 2005; and they found that authors used a wide range of multivariate analysis techniques. These included techniques like discriminate analysis, factor analysis, MANOVA and time-series analysis. They also found that several authors used analytical approaches, such as mathematical modelling and simulation. The authors further observed that the majority of articles used more than one statistical technique.

Articles that made use of survey research used mainly descriptive statistics, correlations, regressions, ANOVA and simulations. Finally, Gupta et al. (2006) reported that descriptive analysis approaches were used more frequently than advanced multivariate statistical techniques. It is evident that output variables, such as research methods, sampling designs and statistical methods, have been investigated in international journal reviews. Such journalspecific reviews are, however, lacking in South Africa.

\section{3}

\section{Research objectives}

The literature discussion above makes it clear that although periodic reviews of journals are undertaken internationally there is a lack of journal-specific reviews in South Africa. There has been no journal-specific evaluation or review of the research published in the SAJEMS; and this study aims to provide insight into the state of South African academic economic and management research by analysing and reporting on the content of this journal from the year 2004 - 2010. The content analysis of the inputs and outputs of the SAJEMS for the seven-year period included 257 articles in total. This time frame was selected on the basis of its being recent, and because of the time and resources available to the researchers.

As an interdisciplinary publication, the SAJEMS addresses a wide variety of topics, with a focus on consumers, firms and/or regulators. The objective of the study was to investigate various input variables (such as number and affiliation of authors) and output variables (aspects discussed in article contents, such as research methodology, sampling designs and statistical methods). Additionally, the following research questions were formulated:

- What are the practices in terms of single and multiple authorship over the sevenyear period?

- Are some sampling designs preferred by certain disciplines?

- Are some sample units preferred by certain disciplines?

- Are some statistical analyses preferred by certain disciplines?

\section{4}

\section{Methodology}

Studies of scholarly literature can be categorised into six dimensions: publishing productivity; comprehensive reviews; meta-analyses; specific journal investigations; methodological investigations; and citation analyses (West, 2007). This study can be categorised as a specific journal investigation, which includes aspects of methodological investigation. Hutchinson and Lovell (2004:386) suggest that methodological approaches tend to be stable over a five-year period. Regarding sampling, a census method applies in this study, and all the articles (257) which appeared in the SAJEMS for the period 2004 - 2010 were included in the sample.

\subsection{Reliability of the study}

Inter-coder reliability is generally considered the defining element for measuring the quality of a review or content analysis (Kolbe \& Burnett, 1991:244). The data for the study were coded by the main researcher and one independent coder. Coder training was provided for the independent coder, using a codebook that gave clear descriptions of all the coding variables to be analysed. Since Krippendorff's alpha measures inter-coder agreement is considered "the most general agreement measure with appropriate reliability interpretations" (Krippendorff, 2004: 221 ), it was used as the measure of inter-coder reliability for the current study. A review of the various opinions concludes that reliability scores of 0.80 or higher are considered acceptable (Neuendorf, 2002:143), although 
Krippendorff (2004:241) maintains that variables with reliabilities of between 0.67 and 0.80 can also be considered for drawing provisional conclusions. The reliability values for the study are reported in Table 1.

Table 1

Krippendorff Alpha reliability values per variable

\begin{tabular}{|l|c|}
\hline \multicolumn{1}{|c|}{ Variable } & Alpha \\
\hline Number of authors & 0.97 \\
\hline Author institution & 0.92 \\
\hline Author occupation & 0.80 \\
\hline Sample unit & 0.77 \\
\hline Sample type & 0.74 \\
\hline Data-collection method/instrument & 0.71 \\
\hline Sampling design & 0.69 \\
\hline Discipline & 0.67 \\
\hline Statistical techniques & 0.63 \\
\hline
\end{tabular}

Table 1 shows clearly that all the variables, except for one (statistical techniques), were above the 0.67 cut-off point, as suggested earlier. The wide variety of statistical techniques used in research may explain the lower reliability results. To address the low reliability scores, the researchers and the coder discussed the disagreements and recoded the data. This process was conducted for all the other variables; and all the corrected values were used in the final data set according to which the findings are reported.

\subsection{Measurement and data analysis}

Previous studies indicate that content analysis is the most commonly-used method for journal analyses. Content analysis is an unobtrusive, observational research method that evaluates the content of publications by identifying and categorising certain characteristics of messages in written or spoken material (Kolbe \& Burnett, 1991:244; Donohue, 2007:252-253). Content analysis can have as its aim the quantification of data, or it can have a more interpretive (qualitative) aim, depending on the research question and the existing knowledge of the topic (Donohue, 2007:252-253). This study will focus on interpretation and induction; the approach used to analyse the content will be an editing approach.

The disadvantages of using content analysis should not be ignored. Coding sheets produce standardised information; this reflects the reductive nature of content analysis when extracting information from complex texts (Bryman \& Bell, 2007:321; Colorado State University, 2009). The focus is on the measurable items, rather than on the true theoretical importance of each article; for this reason, the context in which the articles were written is not addressed.

A codebook was developed from the guidelines provided in previous studies (Baker, 2008; Hutchinson \& Lovell, 2004). The data collection employed a coding sheet, which was used to capture the information relating to the inputs and outputs of the 257 SAJEMS articles. The coding sheet was pre-tested with a convenience sample of 10 articles, and the necessary alterations were made. The following variables were used in the final coding sheet for the study: (1) The number of authors; (2) author occupation; (3) institutional representation; (4) disciplines represented; (5) sample unit; (6) sampling design; (7) data-collection methodology applied; and (8) the statistical analytical techniques used.

\section{5}

\section{Results}

\subsection{Input findings: authorship}

\subsubsection{Academic versus practitioner participation}

The study showed that academic authors who are linked to an institution accounted for 86.7 per cent of those publishing in the SAJEMS 
during the period under review. A further 9 per cent of the studies were collaborative efforts between academics and practitioners. There were only eleven instances (4.3 per cent) where articles were authored solely by practitioners. Contributions by practitioners and collaborations showed a spike in 2005 (21 per cent) and 2008 (31 per cent), but decreased drastically to 6 per cent in 2010 .

\subsubsection{Institutional representation}

Table 2 below shows the breakdown of the institutional representation of those authors publishing in the SAJEMS.

Table 2

Institutional representation

\begin{tabular}{|l|r|r|}
\hline \multicolumn{1}{|c|}{ Institution } & N & Per cent \\
\hline University of Pretoria & 74 & $25.7 \%$ \\
\hline Foreign institutions & 45 & $15.6 \%$ \\
\hline North-West University & 27 & $9.4 \%$ \\
\hline University of South Africa & 21 & $7.3 \%$ \\
\hline University of the Witwatersrand & 21 & $7.3 \%$ \\
\hline University of Stellenbosch & 19 & $6.6 \%$ \\
\hline University of KwaZulu-Natal & 17 & $5.9 \%$ \\
\hline Nelson Mandela Metropolitan University & 17 & $5.9 \%$ \\
\hline Other South African institutions & 14 & $4.9 \%$ \\
\hline University of the Free State & 13 & $4.5 \%$ \\
\hline University of Johannesburg & 8 & $2.7 \%$ \\
\hline University of Cape Town & 3 & $1.0 \%$ \\
\hline Central University of Technology Free State & 2 & $0.7 \%$ \\
\hline University of Zululand & 2 & $0.7 \%$ \\
\hline University of the Western Cape & 1 & $0.3 \%$ \\
\hline Damelin College & 1 & $0.3 \%$ \\
\hline Rhodes University & 1 & $0.3 \%$ \\
\hline University of Fort Hare & 1 & $0.3 \%$ \\
\hline Walter Sisulu University & 1 & $0.3 \%$ \\
\hline Total & $\mathbf{2 8 8}$ & $\mathbf{1 0 0} \%$ \\
\hline *Please & & \\
\hline
\end{tabular}

*Please note that the total exceeds the number of articles owing to several articles from contributors from different institutions.

The best-represented institution is the University of Pretoria, the editorial home of SAJEMS, with 25.7 per cent of the cases contributed by this institution. The next-best represented South African institution is the North-West University (9.4 per cent), followed by the University of South Africa (7.3 per cent) and the University of the Witwatersrand (7.3 per cent). From Table 2, it is evident that the participation of academics from foreign institutions is higher than that of most local institutions. There were 45 instances of foreign participation, accounting for 15.6 per cent of cases, making foreign institutions the second most-published group in the SAJEMS.

\subsubsection{Single versus multiple authorship}

The study showed that 67 per cent of the articles published in the SAJEMS had more than one author. Of the 257 articles examined, only 85 (33 per cent) were single-authored articles. This brings us to the first research question: What were the practices when it comes to single and multiple authorship over the seven-year period?

Figure 1 below illustrates the number of authors in articles published in the SAJEMS in the seven-year period $2004-2010$. 


\section{Figure 1}

Percentage of authors in articles published in SAJEMS 2004 to 2010

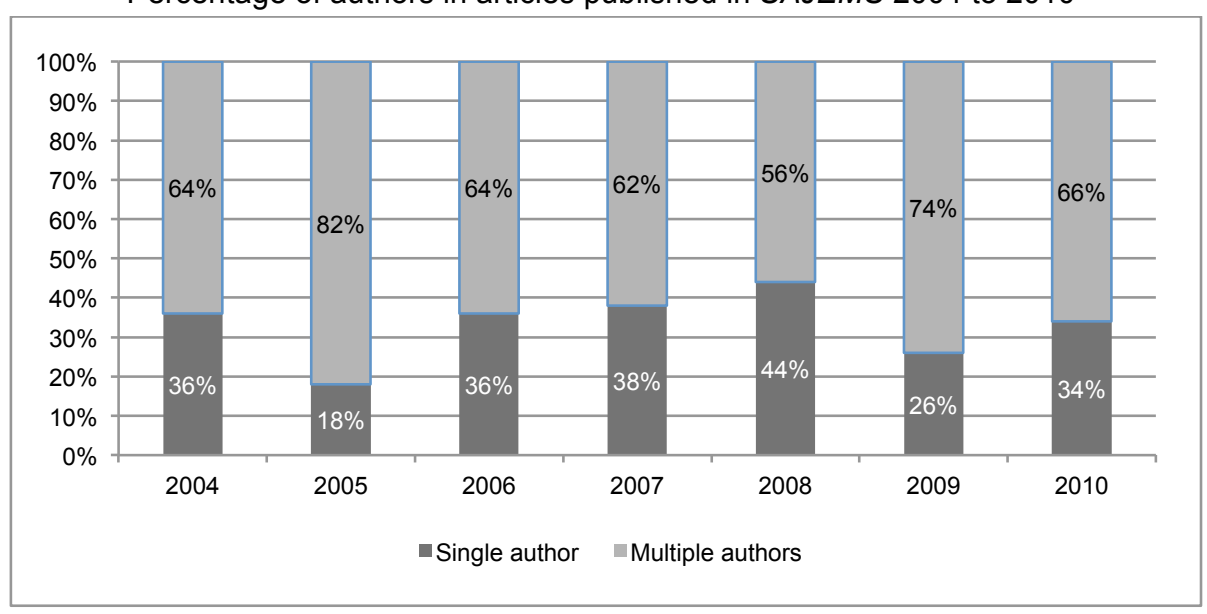

Single-authored studies accounted for 36 per cent of the articles published in the SAJEMS in 2004. This number dropped significantly in 2005, but recovered steadily during the following three years, to pass the 44 per cent mark in 2008. However, the percentage of single-authored articles dropped again to 26 per cent in 2009. Multiple authorship stayed above 60 per cent for the duration of the sevenyear period, with the exception of 2008 , when it dropped to 56 per cent.

\subsection{Output findings: article content}

\subsubsection{Disciplines represented and research design used}

Table 3 below shows the disciplinary representation in the SAJEMS during the seven-year period under analysis. It shows that the journal has remained true to its focus area, with economics and general business/ management being the two best-represented disciplines, accounting for 62 per cent of all articles published. For purposes of clarity, the category of 'general business/management' was created to include all business or management-related research that did not belong to any of the other categories. The third best-represented discipline was human resources ( 9.3 per cent), followed by marketing ( 7.4 per cent). Disciplines grouped in the 'other' category included statistics, information technology (IT) and operations.

Table 3

Academic disciplines represented in the SAJEMS from 2004 to 2010

\begin{tabular}{|l|c|c|}
\hline \multicolumn{1}{|c|}{ Discipline } & N & Per cent \\
\hline Economics & 99 & $38.5 \%$ \\
\hline General business (including management) & 60 & $23.3 \%$ \\
\hline Human resources (including industrial psychology) & 24 & $9.3 \%$ \\
\hline Marketing (including communication) & 19 & $7.4 \%$ \\
\hline Finance and accounting & 22 & $8.6 \%$ \\
\hline Other & 33 & $12.8 \%$ \\
\hline Total & $\mathbf{2 5 7}$ & $\mathbf{1 0 0 \%}$ \\
\hline
\end{tabular}

The analysis of the research designs used showed that 61.5 per cent of the articles published in the SAJEMS during the period
2004 - 2010 employed quantitative research designs, while 33.5 per cent was allocated to qualitative research designs. Of all the research 
designs, only 5 per cent made use of mixed methods. These results are in line with the findings reported by Nilsson et al. (2007).

\subsubsection{Sampling designs used}

The findings on sampling indicate that the articles published in the SAJEMS employed predominantly non-probability sampling designs (40 per cent) (refer to Table 4). It should be noted that for almost half (127 articles) of the studies published in the SAJEMS, the use of sampling was not relevant to studies in the fields of economics and statistics, as well as a number of conceptual articles. It is a matter for concern that of those articles that did employ samples, almost a third did not specify their sampling design.

\section{Table 4}

Sampling designs used in the SAJEMS 2004 to 2010

\begin{tabular}{|l|c|c|}
\cline { 2 - 3 } \multicolumn{1}{c|}{} & N & Per cent \\
\hline Probability & 41 & $31.5 \%$ \\
\hline Non-probability & 52 & $40.0 \%$ \\
\hline Not specifically mentioned & 37 & $28.5 \%$ \\
\hline Total & $\mathbf{1 3 0}^{*}$ & $\mathbf{1 0 0} \%$ \\
\hline
\end{tabular}

*Note that articles listing sampling method as 'not applicable' are omitted from the table.

It must be noted that almost 24 per cent of the articles in the SAJEMS used a census. The most-used non-probability sampling method was convenience sampling (22.9 per cent), followed by purposive sampling (11.4 per cent). The most popular probability sampling methods were simple random sampling and stratified sampling. The second research question addresses whether some sample designs are preferred by certain disciplines. This will be answered below.

Figure 2 illustrates the preferences concerning sampling design used by the main disciplines represented in the SAJEMS. The field of general business overwhelmingly employs nonprobability designs as their sampling approach. Marketing authors demonstrate a more extensive use of probability sampling designs, perhaps because of the importance of having representative studies when dealing with consumer and stakeholder groups. Finally, the great majority of economics articles employing a sample do not contain mention of which sampling design was used for obtaining their sample.

Figure 2

Disciplinary preferences: sampling design

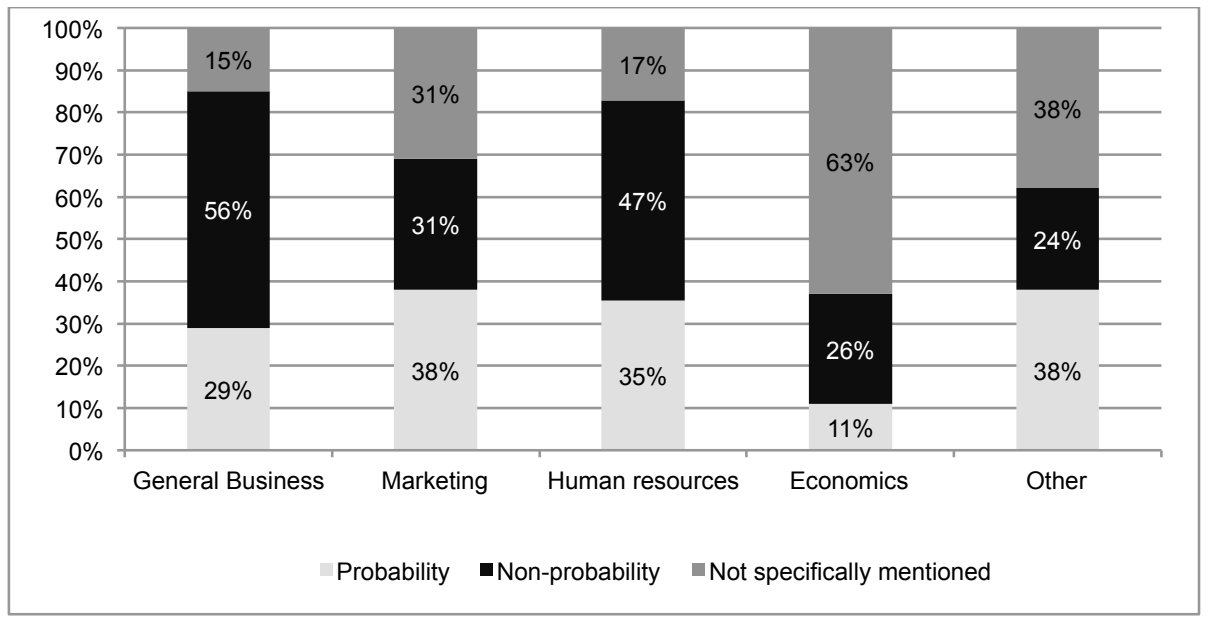




\subsubsection{Data collection instruments}

Table 5 below shows the breakdown of articles published in the SAJEMS during the sevenyear period under review in terms of data collection. A total of 35 per cent of the articles employed secondary data, such as documents and/or databases, as their main source of data. These collection methods were used mostly by writers in economics, statistics and finance/ accounting. The next most-popular source of data was surveys, employed mostly by general business, marketing and human resources. Although the use of surveys showed a decline in 2005 - 2009, it increased again to 48 per cent in 2010 .

Table 5

Data-collection instruments used in articles published in the SAJEMS

\begin{tabular}{|l|c|c|}
\hline \multicolumn{1}{|c|}{ Data collection instrument } & N & Per cent \\
\hline Documents and/or databases & 91 & $35.4 \%$ \\
\hline Survey & 89 & $34.6 \%$ \\
\hline Interviews and focus groups & 18 & $7.0 \%$ \\
\hline Experiment & 10 & $3.9 \%$ \\
\hline Other & 17 & $6.6 \%$ \\
\hline Not applicable (mainly conceptual articles) & 32 & $12.5 \%$ \\
\hline Total & $\mathbf{2 5 7}$ & $\mathbf{1 0 0} \%$ \\
\hline
\end{tabular}

\subsubsection{Sample units}

At this point, it may be relevant to clarify how sample units were coded. Sample units included only those cases where primary data were collected by using a sampling technique. All the cases that used secondary sources for their data analysis, such as documents and databases, were coded as 'other' units. The aim was thus to determine which target groups are sourced when researchers are directly involved in collecting the primary data. A total of 141 articles of the 257 (54.9 per cent) published in the SAJEMS during the period under review focused on a sample unit. Of these, 52 per cent examined professionals, while 16 per cent included adult consumers. Another 24 per cent made use of 'other' units that consisted mainly of documents and/or databases.

Students were the unit of investigation in only 10 of the articles ( 7 per cent), while children were included in only one article. This raises the question of whether some sample units are preferred by certain disciplines when collecting the primary data. This forms the third research question.

Figure 3 below displays the disciplinary preferences concerning the sample units employed in studies published in the SAJEMS during the period under review. It shows that all the disciplines (with the exception of the marketing field) prefer to focus on professionals. Marketing studies seemed to focus more on adults, while human resources was the only discipline that used children as a sample unit (only in one study). Economics used mainly secondary sources as input to test or verify economic models or mathematical formulas; and these were thus mostly classified as 'other' sample units, excluding the subjects of analysis of their secondary sources. If future studies investigate subjects of analysis in the economics field, it may be worthwhile analysing the type of analysis units (for example, households).

\subsubsection{Statistical analyses conducted}

Table 6 below shows the most commonly-used statistical analyses in articles published in the SAJEMS. Each statistical technique used was coded into one of six main categories, as identified by Diamantopoulus and Schlegelmilch (2000). The categories included: (1) descriptive statistics, such as means and frequencies; (2) comparison of groups (independent measures), such as chi-square, t-test and ANOVA; (3) measures of association, such as Spearman or Pearson correlations; (4) multivariate analysis (dependent), such as MANOVA, regression analysis and discriminant analysis; (5) multivariate analysis (interdependent), such as factor analysis and cluster analysis; and (6) other (any technique not belonging to any of 
the previous categories).

Almost 37 per cent of the articles employed descriptive statistics; while 22 per cent of the articles used 'other' methods, which consisted mainly of economic/financial formulas. Only two articles in the 'other' category employed structural equation modelling. The third mostreported method was measures of association that investigate correlations. The least-used method was interdependent multivariate analysis, such as factor analysis.

Figure 3

Disciplinary preferences: sample units

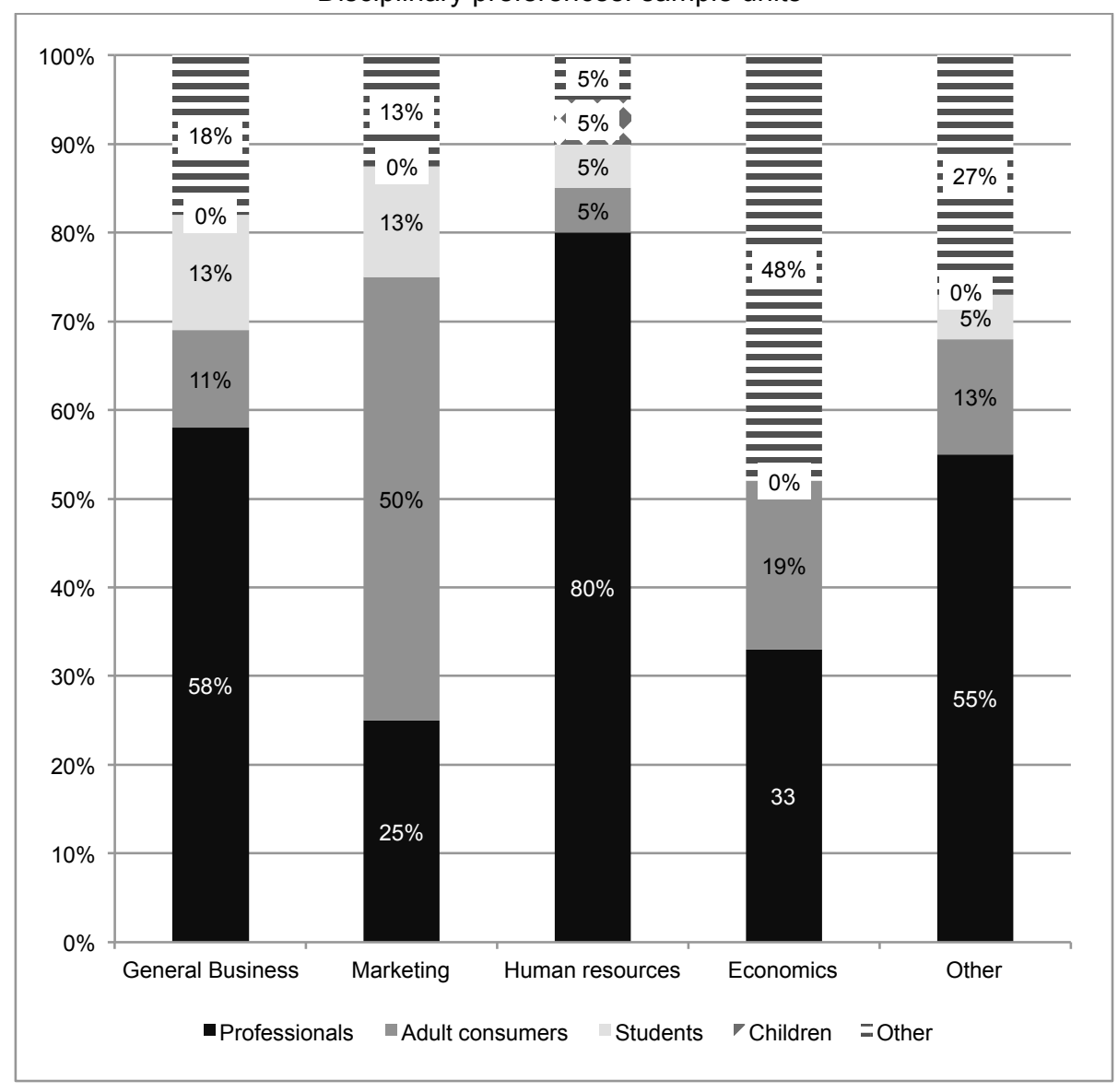

Table 6

Statistical analyses reported in the SAJEMS 2004 to 2010

\begin{tabular}{|l|c|c|}
\hline \multicolumn{1}{|c|}{ Statistical analysis } & N & Per cent \\
\hline Descriptive statistics & 111 & $36.6 \%$ \\
\hline Other & 67 & $22.1 \%$ \\
\hline Measures of association & 39 & $12.9 \%$ \\
\hline Independent measure: comparing groups & 33 & $10.9 \%$ \\
\hline Multivariate analysis: interdependence & 26 & $8.6 \%$ \\
\hline Multivariate analysis: dependent & 27 & $8.9 \%$ \\
\hline Total & $\mathbf{3 0 3}$ & $\mathbf{1 0 0} \%$ \\
\hline
\end{tabular}

*Note that the total exceeds 257 , as some articles used more than one statistical technique. 
The last research question: Are some statistical analyses preferred by certain disciplines? This question is discussed with the aid of Figure 4.

Figure 4 below shows the disciplinary preferences for the different disciplines published in the SAJEMS. It can be seen that descriptive statistics predominate, while economics is shown to have a strong reliance on 'other' analyses, which include economic/financial formulas. Economics also uses more dependent multivariate analysis than any of the other disciplines. It seems that human resources and general business make more use of independent measures when comparing groups than do marketing and economics. Marketing studies tend to make more use of measures of association, such as correlations between constructs.

Figure 4

Disciplinary preferences: Statistical analyses

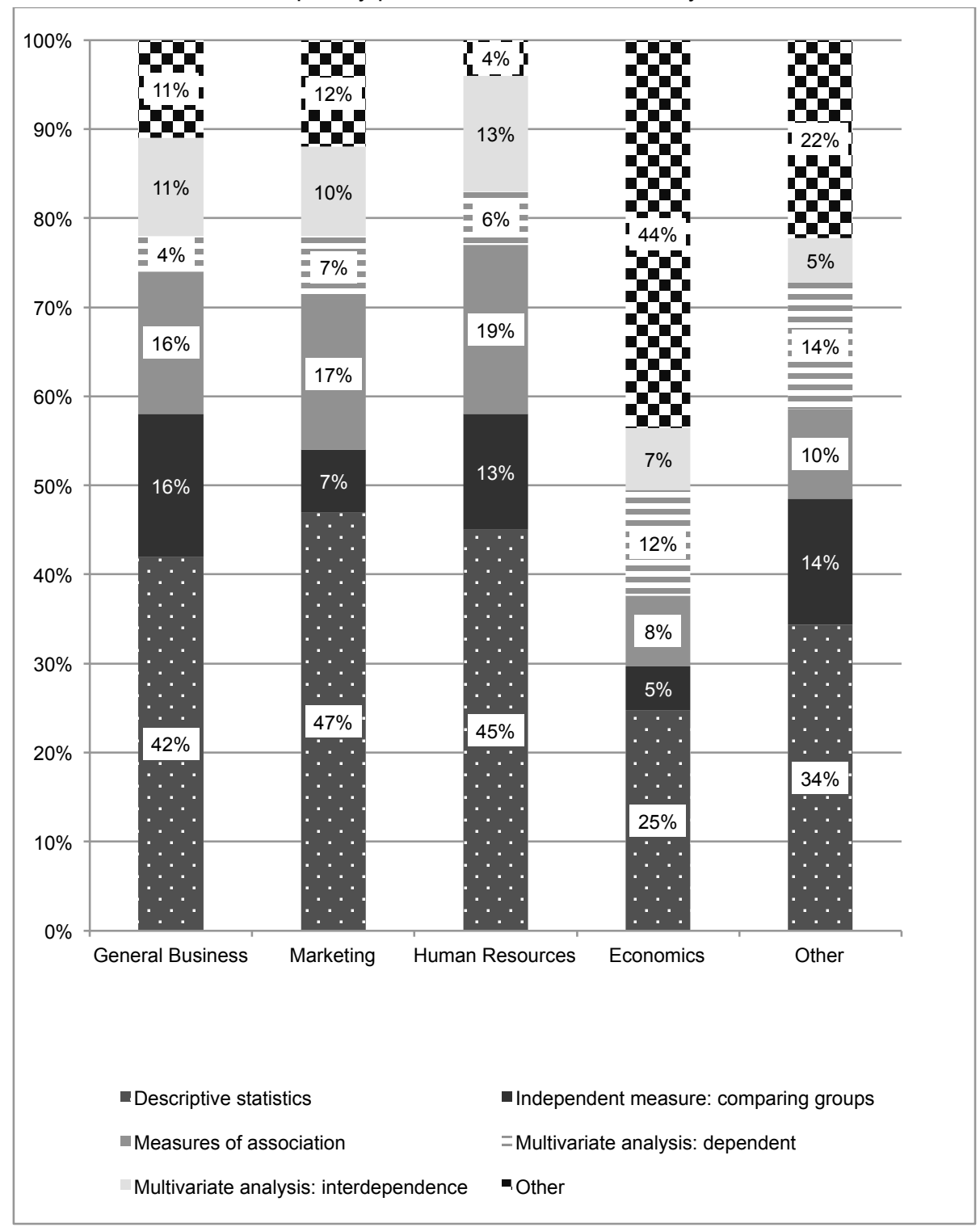




\section{6}

\section{Discussion and managerial implications}

One of the main findings in the study was the decrease in co-authored articles between 2005 and 2008, with the flipside being an increase in single-authored articles. This finding is contrary to the global international trend identified by some researchers (Inkpen \& Beamish, 1994; West, 2007). There is consensus that the quality of an article generally increases when it is done and written in collaboration with fellow researchers (Smart \& Bayer, 1986; Yitzhaki, 1994). It has therefore been suggested that interdisciplinary research and international partnerships should be encouraged by editors to produce even more rich and diverse inputs in research and published findings (Kriek, Beaty \& Nkomo, 2009). Future authors should take note of this, and could also take into consideration that nowadays many research scholarships and grants (such as those from the NRF) seem to encourage interdisciplinary research.

The findings of this study have shown that academics were the main contributors of articles to the $S A J E M S$, with industry practitioners being in the minority (13.3 per cent). This finding concurs with the international research results reported by Hetzel (2000:702), and with those by West (2007:548). Brennan (2004:492) offers some thought on the low practitioner participation rate when he cautions that industry practitioners may not find journal contents applicable or relevant to the world of work. Other possible reasons for the low participation rate by practitioners could be a) the high entry barriers to getting an article published; b) the time-consuming process required by rigorous review processes; c) the lack of time to make extended efforts to write research articles; and/or d) little industry recognition for articles published.

The findings did, however, show an increase in participation in 2008, exceeding 31 per cent of article contributions for the first time; but these unfortunately decreased to 14 per cent in 2009 and to 6 per cent in 2010. It is worth noting that the focus and scope of the SAJEMS is not to encourage practitioner participation per se. However, the current contributions from industry practitioners suggest that there may be an opportunity for the editor to encourage practitioners to contribute to the journal. The SAJEMS may even want to consider publishing a special 'industry' edition. Practitioners may contribute to the scope of the SAJEMS by preparing new paths for debate on the operation and development of sustainable organisations and markets in Africa and abroad.

Malhotra and Peterson (2001:232) also argue that academic researchers should examine those substantive issues that are managerially relevant in order to close the gap between academic and industrial research.

The results show that foreign participation accounted for 15.6 per cent of cases, making foreign institutions the second most-published group, pointing towards a blurring of international borders. This higher foreign participation rate results in an increasingly cosmopolitan body of authors, a strength on which the SAJEMS could build. One would expect this number to increase in future with the SAJEMS supporting the 'open-access policy', whereby the journal's content is made freely available to the public in support of a greater global exchange of knowledge.

Previous research suggests that the institution housing an academic journal is more likely to be the main contributor of content to the journal (Inkpen \& Beamish, 1994). The results in this study underscore this notion, in that the University of Pretoria, which was housing the journal over the period of study, was the main publishing institution in the journal. Furthermore, in line with the trend identified by Otchere $(2003: 220)$, there is also a correlation between the editor of the journal's home institution and the institutional representation in terms of the number of articles published in the SAJEMS. This probably shows that home institutions support their journals; and explains why the University of Pretoria has the highest incidence of articles published (excluding foreign institutions).

This study has revealed that non-probability sampling was most often used. This is supported by the findings by Poon and Rowley (2007). There is, however, some cause for 
concern, as such sample approaches do not allow for the results to be generalised to the whole population, thus limiting the results of the respective studies. Furthermore, such sampling approaches also limit the type of statistical tests that researchers can employ. This finding hopefully underlines the importance of sampling approaches and the limitations that non-probability sampling holds for future authors. On a positive note, many samples used professionals as sampling units. This is in line with the findings reported by both Scandura and Williams (2000), and West (2007).

The findings show that the most-used data collection technique was secondary in nature, more specifically the data extracted from documents and databases. The second mostused technique identified is that of conducting surveys, which is consistent with the findings by West (2007). However, the current study revealed that the survey method declined from 2005 to 2009 , but increased again in 2010 to 48 per cent. This declining trend is in contrast with the results of Inkpen and Beamish (1994), and with those of West (2007). The reason for the recent decline in the use of surveys is not clear, although one may expect a link to the disciplinary fields represented over the years. One could also speculate and state that surveys might be losing their appeal because of 'survey fatigue'.

Many researchers have reported that survey non-response has been increasing. One of the reasons cited was the overexposure of surveys, which results in higher non-response rates, because of more refusals from individuals to participate (Steeh, 1981; Porter, Witcomb \& Weitcer, 2004).

Some of the positive research practices concerning the articles published in the SAJEMS point to the variety of statistical techniques used across the disciplines. This concurs with the findings by Gupta et al. (2006). Economics, for example, uses more dependent multivariate analysis, whereas human resources and general business make more use of independent measures comparing groups. One is hopeful that South African researchers will continue to use (and increase their use of) more robust statistical analyses in their research.

\section{7}

\section{Limitations and directions for future research}

This study has focused on articles published during the seven-year period 2004 - 2010 in the SAJEMS. While sufficient literature exists to suggest that such a time frame is sufficient, a longer period would have provided more information to uncover discernible trends. It is therefore recommended that future studies incorporate a longer time period.

A further limitation might be that the study focused exclusively on one journal, the SAJEMS. While this may be useful to provide a review of a singular publication, it implies that the findings cannot be generalised to other economic and management-related publications in South Africa, or even to international publications. A possible direction for future research would be to conduct similar studies on other South African business journals in order to develop a better understanding of the state of economic and management research conducted in the country as a whole.

The findings showed a decline in the use of surveys. Future research may want to determine the correlation between data-collection techniques and different disciplinary fields. This may shed light on the declining trend in the use of surveys, and whether or not this is linked to a specific discipline.

The sample units investigated in this study focused on sampling, as used in the primary data collection. If future studies investigate subjects of analysis in the field of economics, it may be worthwhile analysing the type of analysis units (for example households) in terms of the secondary sources used.

In conclusion, this content analysis has revealed current research practices, as published in the SAJEMS; and has attempted to shed some light on the nature of research in the economic and management fields. 


\section{References}

ACADEMY OF SCIENCE OF SOUTH AFRICA. 2010. Report on peer review of scholarly journals in the social sciences and related fields. Committee on scholarly publishing in South Africa, August:1-60. Available at: http://www.assaf.org.za/evidence-based-reports/ [accessed 2012-02-28].

ALBAUM, G. \& PETERSON, R.A. 1984. Empirical research in international marketing: 1976-1982. Journal of International Business Studies, 15:161-173.

BAKER, G. 2008. Scholarly publishing in South Africa: Facing reality. South African Journal of Science, 104(11\&12):411-412.

BEATY, D., NKOMO, S. \& KRIEK, H.S. 2006. Management theory-building trends in South Africa: An archival analysis. Management Dynamics, 15(2):2-9.

BOTHA, E., LILFORD, N. \& PITT, L. 2011. South African management literature over the past fifteen years: Content analysis of the three top South African management journals. South African Journal of Business Management, 42(4):89-98.

BRENNAN, R. 2004. Should we worry about an academic-practitioner divide in marketing? Marketing Intelligence \& Planning, 22(5):492-500.

BROWN, I. \& TANNER, M. 2008. The international visibility of South African IS research: An authoraffiliation analysis in the top-ranked IS-centric Journals. South African Computer Journal, December, 42: 14-20.

BRYMAN, A. \& BELL, E. 2007. Business research methods. (2 ${ }^{\text {nd }}$ ed.) London: Oxford University Press. BUSH, A.L. \& GRANT, E.S. 1994. Analysing the content of marketing journals to assess trends in sales force research: 1980-1992. Journal of Personal Selling and Sales Management, 14(3):57-67.

CHAN, K., KAROLYI, G.A. \& RHEE, S.G. 2002. A retrospective evaluation of the Pacific-Basin Finance Journal: 1993-2002. Pacific-Basin Finance Journal, 10:497-516.

CHIA-PING, Y. 2003. Towards an understanding of MIS survey research methodology: current practices, trends and implications for future research, Allied Academic International Conference, 75-79. Available at: http://0-search.proquest.com.innopac.up.ac.za/docprintview/192408205/fulltesxt/12D9 [accessed 2011-0226].

CLARK, S., DICK, K., EPPERECHT, C., DU PLESSIS, L., MATLAKALA, L., MOREMI, M., RAGANYA, L., RICH, E., RICHARDS, C., SEWPERSHAD, N. \& TIMM, V. 2002. Evaluation of scientific articles. UNISA, Psychologia, 28:67-75.

COLORADO STATE UNIVERSITY. 2009. Disadvantages of content analysis. Available at: http://writing. colostate.edu/guides/research/content/com2d3.cfm [accessed 2011-08-21].

COOPER, D.R. \& SCHINDLER, P.S. 2008. Business research methods. (10 ${ }^{\text {th }}$ ed.) New York: McGraw-Hill. DIAMANTOPOULOS, A. \& SCHLEGELMILCH, B.B. 2000. Taking the fear out of data analysis: a stepby-step approach. London, UK: Business Press.

DONOHUE, R. 2007. Management research methods. Melbourne, Australia: Cambridge University Press. GALLAHER, D.R. 2006. Thirty years of published research in the Australian Journal of Management, Australian Journal of Management, 31(1):141-160.

GUPTA, S., VERMA, R. \& VICTORINO, L. 2006. Empirical research published in production and operation management (1992-2005): Trends and future research directions. Production and Operations Management, 15(3):432-448.

HANSON, D. \& GRIMMER, M. 2007. The mix of qualitative and quantitative research in major marketing journals, 1993-2002. European Journal of Marketing, 41(1/2):58-70.

HETZEL, P.L. 2000. Where are we going? Perceptions of French marketing academics. Journal of Marketing Management, 16:697-716.

HOLBERT, N.B. 1997. More key articles in advertising research. Journal of Advertising Research, 17: 33-42.

HOLSAPPLE, C.W., JOHNSON, L.E., MANAKYAN, H. \& TANNER, J. 1993. A citation analysis of business computing research journals. Information and Management, 25:231-244. 
HUTCHINSON, S.R. \& LOVELL, C.D. 2004. A review of methodological characteristics of research published in key journals in higher education: Implications for graduate research training. Research in Higher Education, 45(4):383-403.

INKPEN, A.C. \& BEAMISH, P.W. 1994. An analysis of twenty-five years of research in the Journal of International Business. Journal of International Business, 25(4):703-713.

KOLBE, R.H. \& BURNETT, M.S. 1991. Content-analysis research: an examination of applications with directives for improving research reliability and objectivity. Journal of Consumer Research, September, 18:243-250.

KRIEK, H.S., BEATY, D. \& NKOMO, S. 2009. Theory building trends in international management research: An archival review of preferred methods. South African Journal of Economic and Management Sciences, 12(1):126-135.

KRIGE, S. 2007. An historical review and analysis of the NRF rating system 1983-2005. NRF Historical Review, 13 December:1-115.

KRIPPENDORFF, K. 2004. Reliability in content analysis: Some common misconceptions and recommendations. Human Communication Research, 30(3):411-433.

MACGREGOR, K. 2008. Researcher rating system should stay. Available at: http://www.university worldnews.com [accessed 2012-02-29].

MALHOTRA, N.K. 1996. The impact of the Academy of Marketing Science on marketing scholarship: an analysis of research published in JAMS. Journal of the Academy of Marketing Science, 24(4):53-70.

MALHOTRA, N.K. \& PETERSON, M. 2001. Marketing research in the new millennium: emerging issues and trends. Marketing Intelligence and Planning, 19(4):216-235.

MANTON, E.J. \& ENGLISH, D.E. 2007. The trend towards multiple authorship in business journals. Journal of Education for Business, 82(3):164-168.

NEUENDORF, K.A. 2002. The content analysis guidebook. Thousand Oaks, California: Sage.

NILSSON, J.E., FLORES, L.Y., BERKEL, L., SCHALE, C.L., LINNEMEYER, L.M. \& SUMMER, I. 2007. International career articles: A content analysis of four journals across 34 years, Journal of Vocational Behavior, 70(3):602-613.

OTCHERE, I. 2003 Accounting and Finance at forty: a retrospective evaluation. Accounting \& Finance, 43(2):211-230

PHELAN, S.E., FERREIRA, M. \& SALVADOR, R. 2002. The first twenty years of the Strategic Management journal. Strategic Management Journal, 23:1161-1168.

POON, H.F. \& ROWLEY, C. 2007. Contemporary research on management and human resources in China: A comparative content analysis of two leading journals. Asia Pacific Business Review, 13(1):133-153.

POURIS, A. 2007. The National Research Foundation's rating system: Why scientists let their ratings lapse. South African Journal of Science, 103:439-441.

PORTER, S.P., WITCOMB, M.E. \& WEITCER, W.H. 2004. Multiple surveys of students and survey fatigue. New Directions for Institutional Research, 121:67-73.

SMART, J.C. \& BAYER, A.E. 1986. Author collaboration and impact: a note on citation rates of single and multiple authored articles. Scientometrics, 10(5-6):297-305.

SCANDURA, T.A \& WILLIAMS, E.A. 2000. Research Methodology in Management: Current practices, trends and implications for future research. The Academy of Management Journal, 43(6):1248-1264.

STEEH, C.G. 1981. Trends in Nonresponse Rates, 1952-1979. Public Opinion Quarterly, 59:66-77.

SVENSSON, G. 2006. The paradoxia of top journal(s) in marketing. European Journal of Marketing, 40(11/12):1153-1168.

TAPP, A. 2004. The changing face of marketing academia. European Journal of Marketing, 38(5-6):492499.

VAUGHEN, C.L. 2008. Alternatives to the publication subsidy for research funding. South African Journal of Science, 104(3-4):91-96.

WEST, A. 2006. A commentary on the global position of South African Accounting research. Meditari Accountancy Research, 14(1):121-137.

WEST, D. 2007. Directions in marketing communications research. International Journal of Advertising, 26(4):543-554. 
YALE, L. \& GILLY, M.C. 1988. Trends in advertising research: A look at the content of marketing-oriented journals from 1976 to 1985. Journal of Advertising, 17(1):12-22.

YITZHAKI, M. 1994. Relation of title length of journal articles to number of authors. Scientometrics, 30(1): 321-332. 